\title{
Sistem Pendukung Keputusan Pemilihan Sekolah SMA Swasta Terbaik Dengan Menggunakan Metode PROMETHEE Di Kota Pematangsiantar
}

\author{
Yuni Arista Saragih ${ }^{1}$, Jaya Tata Hardinata ${ }^{2}$, Muhammad Ridwan Lubis ${ }^{3}$ \\ ${ }^{1,2}$ STIKOM Tunas Bangsa, Pematangsiantar \\ ${ }^{3}$ AMIK Tunas Bangsa, Pematangsiantar \\ ysaragih183@gmail.com
}

\begin{abstract}
Selection of the best private schools in embassy cities with the Preference Ranking Organization Method for Enrichment Evaluation (PROMETHEE) method. This decision support system is built through 6 stages. The first stage is collecting data and information through interviews and document analysis. The second stage is processing data and information to get the system design to be built. The third stage is system analysis which includes school data input, weighting criteria with the PROMETHEE method, and alternative ranking with the PROMETHEE method. The Fourth stage is designing the system using the concept of Object Oriented Design. The fifih stage is the implementation of a web-based system. The last step is evaluating the system by comparing the level of accuracy between the PROMETHEE method. With the implementation of the PROMETHEE method for the selection of the best private schools that will result in the ranking of the best private schools, it is expected that in the selection of the best schools that are truly recommended in accordance with the wishes and abilities of students.
\end{abstract}

Keywords: PROMETHEE, Selection, Decision Support System

\begin{abstract}
Abstrak
Penelitian ini bertujuan merancang dan membangun sistem pendukung keputusan untuk pemilihan sekolah swasta terbaik di kota pematangsiantar dengan metode Preference Ranking Organization Method for Enrichnen Evaluation (PROMETHEE). Sistem pendukung keputusan ini di bangun melalui 6 tahap. Tahap pertama adalah pengumpulan data dan informasi melalui wawancara dan analisis dokumen. Tahap kedua adalah pengolahan data dan informasi untuk mendapatkan rancangan sistem yang akan dibangun. Tahap ketiga adalah analisis sistem yang meliputi input data sekolah, pembobotan kriteria dengan metode PROMETHEE, serta perankingan alternatif dengan metodr PROMETHEE. Tahap keempat adalah perancangan sistem menggunakan konsep Objeck Oriented Design. Tahap kelima adalah implementasi sistem berbasis web. Tahap terakhir adalah evaluasi sistem dengan membandingkan tingkat akurasi antara metode PROMETHEE. Dengan penerapan metode PROMETHEE untuk pemilihan sekolah Swasta terbaik yanf akan menghasilkan ranking sekolah swasta terbaik sehingga diharapkan dalam pemilihan sekolah terbaik yang direkomendasikan benar-benar sesuai dengan keinginan, dan kemampuan siswa.
\end{abstract}

Kata Kunci: PROMETHEE, Pemilihan Sekolah, Sistem Pendukung Keputusan

\section{Pendahuluan}

Era perkembangan teknologi yang sangat pesat ini informasi diperoleh dengan sangat mudah dan cepat. Dengan perkembangan komunikasi yang sangat canggih maka seiring dengan itu berkembang pula metode dalam pengambilan keputusan (Decisions Support System) yang akan membantu manusia dalam mengambil keputusan yang tepat dan cepat sasaran serta dapat dipertanggung jawabkan dan menjadi kunci persaingan global dalam keberhasilan. Kota Pematangsiantar merupakan salah satu kota yang sedang berkembang 
dalam bidang ekonomi ditandai dengan banyaknya para investor dalam menanamkan modal usaha seperti hotel, restoran dan lain-lain.

SMA (Sekolah Menengah Atas) merupakan jenjang dalam pendidikan yang bertujuan untuk membentuk kepribadian seorang siswa/i dan mempersiapkan diri, pola pemikiran siswa/i untuk sekolah ke tingkat yang lebih tinggi. Di kota Pematangsiantar dalam menentukan SMA (Sekolah Menengah Atas) terbaik biasanya para siswa/i melakukan penilaian langsung dengan datang ke sekolah yang ingin dituju atau wali atau orang tua siswa/i yang akan mencari informasi melalui media sosial, surat kabar maupun brosur yang berkaitan dengan sekolah tersebut. Dalam melakukan pemilihan sekolah di kota Pematangsiantar banyak sekali kriteria-kriteria yang harus diperhatikan oleh orang tua siswa/i, salah satu kriteria penilaian yang harus dimiliki adalah kualitas sekolah tersebut. Dengan bantuan media sosial, surat kabar maupun brosur sering kali siswa/i dan orang tua merasa ragu dalam menentukan atau memasuki sekolah yang ingin dituju. Keraguan tersebut dikarenakan banyaknya sekolah yang tidak sesuai dengan pengumuman yang ada di media sosial, surat kabar dan brosur tersebut, hal tersebut akan sangat merugikan baik siswa/i maupun orang tuanya.

Dari uraian diatas penulis menemukan masalah yakni adanya keraguan orang tua/wali maupun siswa/i dalam memilih sekolah yang bagus. Dalam melakukan pengambilan keputusan, penelitian ini menerapkan (Preference Rangking Organization Method for Enrichment Evaluation) atau Metode PROMETHEE untuk menentukan sekolah SMA swasta terbaik di kota pematangsiantar. PROMETHEE adalah salah satu metode penentuan urutan atau prioritas untuk analisis multikriteria. Masalah pokoknya adalah keserdehanaan, kejelasan, kestabilan. Dugaan atau dominasi kriteria yang di pergunakan dalam PROMETHEE adalaph menggunakan nilai hubungan antar outrangking [1]. Pada penelitian ini pemilihan Sekolah Menengah Atas Swasta terbaik di kota Pematangsiantar ditentukan oleh beberapa kriteria yaitu akreditasi sekolah, fasilitas sekolah, prestasi sekolah dan kegiatan ekstrakurikuler sekolah. Penelitian terdahulu yang berkaitan dengan penelitian ini adalah yang dilakukan oleh [2] berjudul "Implementasi Metode PROMETHEE Dalam Penentuan Penerima Kredit Usaha Rakyat (KUR)" Metode yang digunakan adalah Metode PROMETHEE yang akan menghasilkan komposisi rangking atau peringkat bagi penerima Kur yang memiliki risiko kredit terendah sampai tertinggi. pada peringkat tersebut berdasarkan nilai yang diperoleh dari net flow dari setiap alternatif, net flow yang tinggi berarti sangat direkomendasikan untuk menjadi penerima KUR karena diperkirakan memiliki risiko kredit yang rendah. Penelitian selanjutnya yang dilakukan oleh [3], [4] berjudul "Analisis PROMETHEE Faktor Penyebab Sulitnya Mahasiswa Menemukan Judul Artikel Ilmiah" pada penelitian ini menggunakan 13 kriteria dan 5 alternatif sehingga menghasilkan perengkingan dengan nilai 0,0896 yaitu faktor kurang referensi dan peringkat kedua yaitu faktor kurang meminta saran/pendapat dengan nilai 0,0255 .

\section{Metodologi Penelitian}

Metode penelitian terdiri atas dua metode, yaitu metode penelitian kualitatif dan metode penelitian kuantitatif. Metode penelitian kuantitatif merupakan salah satu jenis penelitian yang spesifikasinya sistematis terencana, dan terstruktur dengan jelas sejak awal hingga pembuatan desain penelitiannya, sedangkan metode yang berlandaskan pada filsafat positifisme, serta sebagai metode artistik karena proses penelitian lebih bersifat seni (kurang terpola), dan disebut metode interpretive karena data hasil penelitian lebih berkenaan dengan intepretasi terhadap data yang ditemukan di lapangan ialah pengrtian dari penelitian kuantitatif[5], [6].

\subsection{Metode Pengumpulan Data}

Metode ini berisi penjelasan tentang cara pengumpulan data yang digunakan. Secara umum dalam menggunakan metode untuk pengumpulan data untuk memecahkan 
masalah dalam penyelesaian kasus yang diangkat adalah wawancara, observasi, dan studi literatur [7].

\subsection{Studi Literatur}

Perlu dipelajari beberapa literature - literature yang digunakan untuk mencapai suatu tujuan yang akan ditentukan. Dalam penelitian ini langkah awal yang dilakukan adala studi pustaka . dalam penelitian studi pustaka ini untuk melengkapi pengetahuan dasar dan teori-teoriyang digunakan [8].

\subsection{Mengumpulkan Data}

Pada tahap ini, data diperoleh dari Cabang Kantor Dinas Pendidikan Pematangsiantar yang bertempat di Jl.Pdt J. Wismar Saragih No 3 Pematangsiantar [9].

\subsection{Penentuan Kriteria dan Sub Kriteria}

Melakukan penentuan kriteria dan sub kriteria untuk proses perhitungan dengan metode PROMETHEE [10]. Dalam hal ini menentukan alternative dan kriteria yang akan menjadi acuan pengambilan keputusan. Diuraikan sebagai berikut:

Tabel 1. Data Alternatif

\begin{tabular}{l}
\hline \multicolumn{1}{c}{ Alternatif } \\
\hline SMA Methodist (A1) \\
SMA Tamansiswa (A2) \\
SMA Perguruan Keluarga (A3) \\
SMA Kartika I-4 (A4) \\
SMA RK Bintang Timur (A5) \\
SMA Teladan (A6) \\
SMA Budi Mulia (A7) \\
MAS Alwashliyah (A8) \\
SMA Sultan Agung (A9) \\
SMA GUPPI (A10) \\
\hline
\end{tabular}

Data Alternatif ialah data Sekolah Swasta yang akan menjadi acuan dalam pengambilan sebuah keputusan.

Tabel 2. Data Kriteria

\begin{tabular}{l}
\hline \multicolumn{1}{c}{ Kriteria } \\
\hline Akreditasi (C1) \\
Fasilitas (C2) \\
Prestasi (C3) \\
Ekstrakurikuler (C4) \\
\hline
\end{tabular}

Data Kriteria ialah data yang akan menjadi acuan dalam pengambilan sebuah keputusan.

Tabel 3. Data Kriteria Akreditasi

\begin{tabular}{ll}
\hline Keterangan & Akreditasi \\
\hline Sangat Baik (A) & 4 \\
Baik (B) & 3 \\
Cukup (C) & 2 \\
Sangat Cukup (D) & 1 \\
\hline
\end{tabular}

Akreditasi Sekolah ialah nilai yang diberikan dinas pendidikan kota Pematangsiantar.

Tabel 4. Data Kriteria Fasiliitas

\begin{tabular}{ll}
\hline Keterangan & Fasilitas \\
\hline Sangat Lengkap & 4 \\
Lengkap & 3 \\
Kurang Lengkap & 2 \\
Tidak Ada & 1 \\
\hline
\end{tabular}


Fasilitas ialah yang berisi tentang kelengkapan sekolah dalam menjalankan kegiatan belajar mengajar.

Tabel 5. Data Kriteria Prestasi

\begin{tabular}{ll}
\hline Keterangan & Prestasi \\
\hline Tingkat Nasional & 4 \\
Tingkat Daerah & 3 \\
Antar Sekolah & 2 \\
Tidak ada & 1 \\
\hline
\end{tabular}

Prestasi sekolah ialah yang berisi prestasi sekolah dalam mengikuti olimpiade-olimpiade antar sekolah, tingakat daerah maupun tingkat provinsi.

Tabel 6. Data Kriteria Ekstrakulikuler

\begin{tabular}{ll}
\hline Keterangan & Ekstrakurikuler \\
\hline Ada dan aktif & 4 \\
Ada dan Kurang Aktif & 3 \\
Ada dan Berhenti & 2 \\
Tidak Ada & 1 \\
\hline
\end{tabular}

Ekstrakurikuler ialah yang berisi tentang kelengkapan maupun keaktifan sekolah dalam mengadakan ekstrakurikuler.

Tabel 7. Data Alternatif Dan Kriteria Sekolah

\begin{tabular}{ccccc}
\hline Alternatif & (C1) & (C2) & (C3) & (C4) \\
\hline A1 & 4 & 3 & 3 & 4 \\
A2 & 4 & 2 & 4 & 4 \\
A3 & 4 & 3 & 1 & 3 \\
A4 & 3 & 3 & 2 & 3 \\
A5 & 3 & 4 & 3 & 3 \\
A6 & 4 & 3 & 4 & 4 \\
A7 & 4 & 4 & 2 & 4 \\
A8 & 3 & 2 & 3 & 3 \\
A9 & 4 & 3 & 2 & 4 \\
A10 & 2 & 2 & 1 & 3 \\
\hline
\end{tabular}

Data Alternatif dan Kriteria Sekolah ialah yang memiliki data Alternatif dan Kriteria sekolah terbaik.

\subsection{Implementasi}

Metode penelitian yang digunakan adalah salah satu dari bagian Sistem Pendukung Keputusan (SPK) yaitu metode PROMETHEE metode yang bersifat pernentua uruta dan multikriteria dengan rumus perhitungan preferensi multikriteria net flow, entering flow dan leaving flow. [11] Metode PROMETHEE ini dikenal karena konsepnya yang efisien dan simple, metode ini sangat mudah untuk diterapkan selain itu juga untuk menyelesaikan masalah yang berhubungan dengan multikriteria.

\section{Hasil dan Pembahasan}

Adapun langkah-langkah yang dilakukan dalam menyelesaikan suatu permasalahan yang digunakan metode PROMETHEE adalah sebagai berikut:

a. Menentukan alternative dan kriteria akan menjadi acuan pengambilan keputusan seperti yang ditunjukkan pada table 1 dan 2

b. Menentukan bobot penilaian untuk semua kriteria, bobot penilaian pada perangkingan SMA swasta terbaik ini didapat dari hasil observasi, wawancara dan diskusi dengan pihak terkait. Berikut penentuan bobot: 
Tabel 8. Nilai Bobot Alternatif Dari Tiap Kriteria

\begin{tabular}{ccccccccc}
\hline Alternatif & \multicolumn{3}{c}{ Kriteria } & \multicolumn{5}{c}{ Hasil } \\
\cline { 2 - 6 } & C1 & $\mathbf{C 2}$ & $\mathbf{C 3}$ & $\mathbf{C 4}$ & & & & \\
\cline { 2 - 6 } (A1) & $\mathbf{1 0}$ & $\mathbf{8}$ & $\mathbf{7}$ & $\mathbf{5}$ & & & & \\
(A2) & 4 & 3 & 3 & 4 & 40 & 24 & 21 & 20 \\
(A3) & 4 & 3 & 4 & 4 & 40 & 16 & 28 & 20 \\
(A4) & 3 & 3 & 2 & 3 & 40 & 24 & 7 & 15 \\
(A5) & 3 & 4 & 3 & 3 & 30 & 24 & 14 & 15 \\
(A6) & 4 & 3 & 4 & 4 & 40 & 24 & 21 & 15 \\
(A7) & 4 & 4 & 2 & 4 & 40 & 32 & 14 & 20 \\
(A8) & 3 & 2 & 3 & 3 & 30 & 16 & 21 & 15 \\
(A9) & 4 & 3 & 2 & 4 & 40 & 24 & 14 & 20 \\
(A10) & 2 & 2 & 1 & 3 & 20 & 16 & 7 & 15 \\
\hline
\end{tabular}

Tabel 8 diatas merupakan nilai bobot alternatif yang ditentukan berdasarkan dari penilaian tiap kriteria. Berikut perhitungan manual untuk Nilai:

Rumus yang digunakan yakni :

$\mathrm{N}=$ Alternatif $\times$ Bobot Kriteria

$\mathrm{A} 1=4 \times 10=40$

$\mathrm{A} 1=3 \times 8=24$

$\mathrm{A} 1=3 \times 7=21$

$\mathrm{A} 1=4 \times 5=20$

Dapat dilanjutkan hingga A10 sama dengan cara yang seperti diatas.

c. Langkah ketiga, Menghitung Nilai Preferensi

Rumus Menghitung nilai Preferensi setiap nilai kriteria dari alternatif Untuk :

$\mathrm{f} 1(\mathrm{~d})=\mathrm{A} 1-\mathrm{A} 2$

$\mathrm{H}(\mathrm{d})=\{0$ jika $\mathrm{d} \leq 0$ dan 1 jika $\mathrm{d}>0\}$

Berikut implementasi perhitungan nilai preferensi :

$\mathrm{f} 1(\mathrm{~d})=\mathrm{A} 1-\mathrm{A} 2$

(d) $=40-40=0$

$\mathrm{d} \leq 0$

maka $\mathrm{H}(\mathrm{d})=0$

(d) $=24-16=1$

d $>1$

maka $\mathrm{H}(\mathrm{d})=1$

(d) $=21-28=-7$

$\mathrm{d} \leq 0$

maka $\mathrm{H}(\mathrm{d})=0$

(d) $=20-20=0$

$\mathrm{d} \leq 0$

Maka $\mathrm{H}(\mathrm{d})=0$

Menghitung nilai preferensi begitu selanjutnya hingga selesai.

d. Perhitungan Nilai Indeks Preferensi Multikriteria

$\mathrm{P}(\mathrm{A} 1, \mathrm{~A} 2)=(\mathrm{Yn} 1+\mathrm{Yn} 2+\ldots . . \mathrm{yn}) 1 / \mathrm{Yn}$

$\mathrm{P}(\mathrm{A} 2, \mathrm{~A} 1)=(\mathrm{Yn} 1+\mathrm{Yn} 2+\ldots . . \mathrm{yn}) 1 / \mathrm{Yn}$

\begin{tabular}{|c|c|c|c|c|c|c|c|c|c|c|c|}
\hline $\mathrm{A} 1, \mathrm{~A} 2$ & 0 & + & 1 & + & 0 & + & 0 & $=$ & $1 / 4$ & $=$ & 0,25 \\
\hline $\mathrm{A} 2, \mathrm{~A} 1$ & 0 & + & 0 & + & 1 & + & 0 & & $1 / 4$ & $=$ & 0,25 \\
\hline $\mathrm{A} 1, \mathrm{~A} 3$ & 0 & + & 0 & + & 1 & + & 1 & $=$ & $2 / 4$ & $=$ & 0,50 \\
\hline $\mathrm{A} 3, \mathrm{~A} 1$ & 0 & + & 0 & + & 0 & + & 0 & $=$ & $0 / 4$ & $=$ & 0,00 \\
\hline $\mathrm{A} 1, \mathrm{~A} 4$ & 1 & + & 0 & + & 1 & + & 1 & $=$ & $3 / 4$ & $=$ & 0,75 \\
\hline
\end{tabular}




\begin{tabular}{l|lllllllllll}
$\mathrm{A} 4, \mathrm{~A} 1$ & 0 & + & 0 & + & 0 & + & 0 & $=$ & $0 / 4$ & $=$ & 0,00 \\
$\mathrm{~A} 1, \mathrm{~A} 5$ & 1 & + & 0 & + & 0 & + & 1 & $=$ & $2 / 4$ & $=$ & 0,50 \\
$\mathrm{~A} 5, \mathrm{~A} 1$ & 0 & + & 1 & + & 0 & + & 0 & $=$ & $1 / 4$ & $=$ & 0,25 \\
$\mathrm{~A} 1, \mathrm{~A} 6$ & 0 & + & 0 & + & 0 & + & 0 & $=$ & $0 / 4$ & $=$ & 0,00 \\
$\mathrm{~A} 6, \mathrm{~A} 1$ & 0 & + & 0 & + & 1 & + & 0 & $=$ & $1 / 4$ & $=$ & 0,25 \\
$\mathrm{~A} 1, \mathrm{~A} 7$ & 0 & + & 0 & + & 1 & + & 0 & $=$ & $1 / 4$ & $=$ & 0,25 \\
$\mathrm{~A} 7, \mathrm{~A} 1$ & 0 & + & 1 & + & 0 & + & 0 & $=$ & $1 / 4$ & $=$ & 0,25 \\
$\mathrm{~A} 1, \mathrm{~A} 8$ & 1 & + & 1 & + & 0 & + & 1 & $=$ & $2 / 4$ & $=$ & 0,50 \\
$\mathrm{~A} 8, \mathrm{~A} 1$ & 0 & + & 0 & + & 1 & + & 0 & $=$ & $1 / 4$ & $=$ & 0,25 \\
$\mathrm{~A} 1, \mathrm{~A} 9$ & 0 & + & 0 & + & + & + & $=$ & $1 / 4$ & $=$ & 0,25 \\
$\mathrm{~A} 9, \mathrm{~A} 1$ & 1 & + & + & + & + & 1 & $=$ & $3 / 4$ & $=$ & 0,75 \\
$\mathrm{~A} 1, \mathrm{~A} 10$ & 1 & + & 1 & + & + & $=$ & $1 / 4$ & $=$ & 1,00
\end{tabular}

Berikut kesimpulan hasil sebelum menentukan rangking didapat dari nilai indeks preferensi multikriteria yang dibuat dalam bentuk tabel 9:

Tabel 9. Nilai Indeks Preferensi Multikriteria

\begin{tabular}{cccccccccccc}
\hline & A1 & A2 & A3 & A4 & A5 & A6 & A7 & A8 & A9 & A10 & Jumlah \\
\hline A1 & 0 & 0,25 & 0,5 & 0,75 & 0,5 & 0 & 0,25 & 0,75 & 0,25 & 1 & 4,25 \\
A2 & 0,25 & 0 & 0,5 & 0,75 & 0,75 & 0 & 0,25 & 0,75 & 0,25 & 0,75 & 4,25 \\
A3 & 0 & 0,25 & 0 & 0,25 & 0,25 & 0 & 0 & 0,5 & 0 & 0,5 & 1,75 \\
A4 & 0 & 0,25 & 0,25 & 0 & 0 & 0 & 0 & 0,25 & 0 & 0,75 & 1,50 \\
A5 & 0,25 & 0,25 & 0,5 & 0,5 & 0 & 0,25 & 0,25 & 0,25 & 0,5 & 0,75 & 3,50 \\
A6 & 0,25 & 0,25 & 0,5 & 0,75 & 0,75 & 0 & 0,25 & 1 & 0,25 & 1 & 5,00 \\
A7 & 0,25 & 0,25 & 0,75 & 0,75 & 0,5 & 0,25 & 0 & 0,75 & 0,25 & 1 & 4,75 \\
A8 & 0 & 0 & 0,25 & 0,25 & 0 & 0 & 0,25 & 0 & 0,25 & 0,5 & 1,50 \\
A9 & 0 & 0,25 & 0,5 & 0,5 & 0,5 & 0 & 0 & 0,75 & 0 & 1 & 3,50 \\
A10 & 0 & 0 & 0 & 0 & 0 & 0 & 0 & 0 & 0 & 0 & 0 \\
Jumlah & 1 & 1,75 & 3,75 & 4,5 & 3,25 & 0,5 & 1,25 & 5 & 1,75 & 7,25 & \\
\hline
\end{tabular}

e. PROMETHEE Rangking

Perhitungan arah preferensi dipertimbangkan berdasarkan nilai indeks :

1. Leaving Flow

$$
\phi^{+}=\frac{1}{1-n} \sum_{x \in A} \varphi(a, x) \Phi^{+}=\frac{1}{1-n} \sum_{x \in A} \varphi(a, x)
$$

Berikut implementasi dari persamaan 4 :

$\begin{array}{lll}\text { A1 } & 4,25 /(4-1) & =1,416667 \\ \text { A2 } & 4,25 /(4-1) & =1,416667 \\ \text { A3 } & 1,75 /(4-1) & =0,58333 \\ \text { A4 } & 1,50 /(4-1) & =0,5 \\ \text { A5 } & 3,50 /(4-1) & =1,166667 \\ \text { A6 } & 5,00 /(4-1) & =1,166667 \\ \text { A7 } & 4,75 /(4-1) & =1,583333 \\ \text { A8 } & 1,50 /(4-1) & =0,5 \\ \text { A9 } & 3,50 /(4-1) & =1,166667 \\ \text { A10 } & 0,00 /(4-1) & =0\end{array}$

Keterangan : nilai a1 smpai dengan a10 diambil dari 3.9 dalam bentuk baris yang terdapat dalam baris jumlah.

2. Entering Flow

$$
\begin{aligned}
\Phi^{-}=\frac{1}{1-n} \sum_{x \in A} \varphi(x, a) \Phi^{-}= & \frac{1}{1-n} \sum_{x \in A} \varphi(x, a) \\
1 /(4-1) & =0,33333 \\
1,75 /(4-1) & =0,58333 \\
3,75 /(4-1) & =1,25 \\
4,5 /(4-1) & =1,5 \\
3,25 /(4-1) & =1,0833 \\
0,5 /(4-1) & =0,16667 \\
1,25 /(4-1) & =0,41667 \\
5 /(4-1) & =1,66667 \\
1,75 /(4-1) & =0,58333
\end{aligned}
$$


Keterangan: nilai a1 smpai dengan a10 diambil dari 3.9 dalam bentuk kolom yang terdapat dalam bkolom jumlah.

3. Net Flow

$$
\phi(A)=\phi^{+}(a)-\phi^{-}(a) \phi(A)=\phi^{+}(a)-\phi^{-}(a)
$$

Keterangan:

a) $(a, x)=$ alternative a menunjukan preferensi bahwa alternative a lebih baik dari alternative.

b) $(\mathrm{x}, \mathrm{a})=$ menunjukan preferensi bahwa alternative lebih baik daripada alternative $\mathrm{x}$.

c) (a) = Leaving flow, urutan parsial digunakan untuk menentukan urutan prioritas pada proses PROMETHEE.

d) (a) = Entering flow, urutan parsial yang digunakan untuk menentukan urutan prioritas pada proses PROMETHEE.

e) (a) = Net flow, untuk menghasilkan urutan yang lengkap digunakan keputusan akhir penentuan ururan dalam menyelesaikan masalah.

Pada tahap ini, setelah melalui tahapan literatur hingga tahapan pengujian maka dapat disimpulkan hasil dari tahapan tersebut berupa hasil implementasi perhitungan Net Flow seperti pada tabel berikut:

Tabel 10. Perangkingan Net Flow

\begin{tabular}{lcll}
\hline \multicolumn{1}{c}{ Nama } & $\begin{array}{c}\text { Perhitungan Net } \\
\text { Flow }\end{array}$ & Net Flow & Urutan \\
\hline SMA Teladan (A6) & $1,666-0,1666$ & 1,5 & 1 \\
SMA Budi Mulia (A7) & $1,5833-0,4166$ & 1,16667 & 2 \\
SMA Methodist (A1) & $1,4166-0,3333$ & 1,08333 & 3 \\
SMA Tamansiswa (A2) & $1,4166-0,5833$ & 0,83333 & 4 \\
SMA Sultan Agung (A9) & $1,1666-0,5833$ & 0,58333 & 5 \\
SMA RK Bintang Timur (A5) & $1,1666-1,0833$ & 0,08333 & 6 \\
SMA YPK (A3) & $0,58333-1,5$ & $-0,91667$ & 7 \\
SMA Kartika I-4 (A4) & $-0,5-0,643$ & $-0,143$ & 8 \\
MAS Alwasliyah (A8) & $0,5-1,6666$ & $-1,16667$ & 9 \\
SMA GUPPI (A10) & $0-2,41666$ & $-2,41667$ & 10 \\
\hline
\end{tabular}

Dari tabel 10 menunjukkan bahwa SMA Swasta Teladan (A6) menjadi sekolah yang terbaik di kota Pematangsiantar, dengan posisi kedua SMA Swasta Budi Mulia (A7), posisi ketiga SMA Swasta Sultan Agung (A1) dan disusul oleh sekolah SMA Swasta lain.

\section{Kesimpulan}

Berdasarkan uraian yang telah di paparkan bab demi bab dari skripsi yang penulis buat, penulis dapat menyimpulkan bahwa :

a) Sistem pendukung keputusan pemilihan sekolah SMA Swasta Terbaik Dengan Menggunakan Metode PROMETHEE di Kota Pematangsiantar sistem berbasis web dengan menggunakan aplikasi Macromedia Dreamweaver CS 6.0 dan MySQL Server.

b) Hasil akhir yang diperoleh baik menggunakan perhitungan secara manual maupun secara komputerisasi menunjukkan hasil yang sama, yaitu alternatif A6 yang terpilih sebagai alternatif terbaik dalam menentukan SMA Swasta Terbaik Di Kota Pematangsiantar. 


\section{Daftar Pustaka}

[1] A. P. Windarto, "Implementasi metode topsis dan saw dalam memberikan reward pelanggan," Kumpul. J. Ilmu Komput., vol. 04, no. 01, pp. 88-101, 2017.

[2] G. R. Iriane, Ernwati, and I. Wisnubhadra, "Analisis penggabungan metode saw dan metode topsis untuk mendukung keputusan seleksi penerimaan dosen," Semin. Nas. Inform. 2013 (semnasIf 2013), vol. 2013, no. semnasIF, pp. 1-7, 2013.

[3] R. M. Wibowo et al., "Penerapan Metode Profile Matching untuk Aplikasi Multi Criteria Decision Making (Studi Kasus: Pemilihan Guru Berprestasi)," Semin. Nas. Teknol. Inf. dan Multimed., pp. 6-8, 2015.

[4] H. Muslim and M. A. M. Baihaqi, "Sistem Pendukung Keputusan Untuk Pemilihan Hotel dengan Simple Additive Weighting (SAW) Berbasis Web," Semin. Nas. Teknol. Inf. dan Multimed., pp. 6-7, 2016.

[5] F. T. Wulandari and F. B. Hartono, "Penentuan Produk Kerajianan Unggulan Dengan Menggunakan MADM-TOPSIS," Magistra, no. 87, pp. 11-16, 2014.

[6] S. Mallu, "Sistem pendukung keputusan penentuan karyawan kontrak menjadi karyawan tetap menggunakan metode topsis," J. Ilm. Teknol. Inf. Terap., vol. I, no. 2, pp. 36-42, 2015.

[7] P. Sulistyorini, "Pemodelan Visual dengan Menggunakan UML dan Rational Rose," J. Teknol. Inf. Din. Vol., vol. XIV, no. 1, pp. 23-29, 2009.

[8] A. Syarif et al., "Jurnal TEKNOIF ISSN : 2338-2724 SISTEM INFORMASI GEOGRAFIS SARANA PADA Jurnal TEKNOIF ISSN : 2338-2724,” vol. 4, no. 2, pp. 40-50, 2016.

[9] M. A. S. Suripto and R. A. Triyono, "Pembangunan Sistem Informasi Akta Kelahiran," Indones. J. Netw. Secur., vol. 3, no. 3, pp. 33-40, 2014.

[10] S. Ria, S. Siregar, and P. Sundari, "Rancangan Sistem Informasi Pengelolaan Data Kependudukan Desa ( Studi Kasus di Kantor Desa Sangiang Kecamatan Sepatan Timur )," J. SISFOTEK Glob., vol. 6, no. 1, 2016.

[11] M. R. R. Widodo, M. R. Zainuddin, and L. S. Nusantara, "Sistem Informasi Dan Pengolahan Data Kursus Mobil Berbasis Web Dengan Sms," JIMP - J. Inform. Merdeka Pasuruan, vol. 1, no. 3, pp. 85-104, 2016.

[12] R. Khoirunnissa, R. R. Isnanto, and K. T. Martono, "Pembuatan Aplikasi Web Manajemen Laundry dan Integrasi Data dengan Web Service," J. Teknol. dan Sist. Komput., vol. 4, no. 1, pp. 93-101, 2016. 